Original Research Article

\title{
Adverse effects of topiramate in patients with epilepsy in a tertiary care hospital: observational study
}

\author{
Subahan S. P. ${ }^{1}$, Kulandaiammal M. ${ }^{1 *}$, Arunan S. ${ }^{2}$
}

\begin{abstract}
${ }^{1}$ Department of Pharmacology, ${ }^{2}$ Department of Neurology, Govt. Stanley Medical College, Chennai, Tamil Nadu, India
\end{abstract}

Received: 28 January 2019 Accepted: 28 February 2019

\section{*Correspondence to:}

Dr. Kulandaiammal M., Email: drkulandpharma@ gmail.com

Copyright: (C) the author(s), publisher and licensee Medip Academy. This is an openaccess article distributed under the terms of the Creative Commons Attribution NonCommercial License, which permits unrestricted noncommercial use, distribution, and reproduction in any medium, provided the original work is properly cited.

\begin{abstract}
Background: Epilepsy is a common chronic neurological disorder characterized by paroxysmal cerebral dysrhythmia. Conventional antiepileptic drugs such as Phenytoin, carbamazepine, phenobarbitone and sodium valproate, have been proven to have good therapeutic effects. There are currently more than 10 different adjuvants which are approved for use in epileptics. Topiramate, a second-generation antiepileptic drug, is being used for several types of partialonset and generalized-onset seizures. Effective treatment of epilepsy depends on medication compliance. The incidence of adverse effects is an important issue when antiepileptic drugs are prescribed to treat epilepsy. This study was done in Department of Neurology to observe the adverse effects of Topiramate in patients with epilepsy in a Tertiary care hospital.

Methods: For this study 100 patients receiving topiramate as an adjuvant drug along with regular anti epileptic drugs were enrolled in the study for prescheduled three months. Data of the patients were collected.

Results: In this study we observed that paresthesia (31\%) was the commonly noted adverse effect followed by cognitive impairment (24\%), sleepiness (19\%), nausea (13\%), anorexia (9\%) and weight loss (4\%).

Conclusions: Topiramate is a potent antiepileptic drug effective against most seizure types and has relatively favourable pharmacokinetic profile. It is appropriate for initial monotherapy as well as for adjuvant therapy in refractory patients. The major problem limiting its use is the frequent occurrence of cognitive adverse effects, especially expressive language dysfunction, which are reversible upon discontinuation of the medication.
\end{abstract}

Keywords: Antiepileptic drugs, Adverse effects, Epilepsy, Topiramate

\section{INTRODUCTION}

Topiramate (TPM), a second-generation antiepi-leptic drug, is being widely used for the treatment of partial-onset and generalized-onset seizures and is a broad-spectrum agent. ${ }^{1}$ It is also effective as a prophylactic agent against migraine headaches. ${ }^{2}$ TPM was first approved for prescription use in 1996.

The most common side effects encountered on clinical uses of topiramate are negative effects on cognition, paresthesias, spontaneous glaucoma, weight loss, renal stones, and acidemia. ${ }^{3}$ Although it is usually safe and well- tolerated, adverse effects limit use in about $25 \%$ of patients. The most salient of these is cognitive dysfunction, especially problems with expressive speech and verbal memory.

TPM has multiple mechanisms of action, including inhibition of voltage-dependent sodium and calcium ion channels, potentiation of gamma-amino butyric acid (GABA) inhibition, blocking of $\alpha$-amino-3-hydroxy-5methyl-4-isoxazole propionic acid/kainate receptors, enhancement of potassium currents, and inhibition of several carbonic anhydrase isozymes. ${ }^{5}$ 
Effective treatment of epilepsy depends on medication compliance and studies indicate that drug tolerability is a significant limiting factor in medication maintenance. The incidence of adverse effects is an important issue when antiepileptic drugs are prescribed clinically. ${ }^{6}$

This study was done in department of neurology to observe the adverse effects of topiramate in patients with epilepsy in a tertiary care hospital.

\section{METHODS}

The observational study conducted at the Department of Neurology, Govt. Stanley Medical College Hospital, Chennai, for the 3 months. The sample size was 100 patients in the present study.

\section{Inclusion criteria}

- Patients with seizure disorder of age above 18 years of age and below 60 years of age.

- Both males and females.

- Patients who are willing to participate in the study.

- Patients who are willing to give the informed consent in the study.

\section{Exclusion criteria}

- Patients below 18 years of age and above 60 years of age

- Patients who are not willing to participate in the study.

- Patients who are critically ill

- Patients with past H/O gastrointestinal diseases.

- Patients with past H/O renal disease.

- Patients with past H/O liver disease

\section{Study procedure}

This study was conducted after obtaining approval from the Institutional Ethics Committee. This was a hospital based, observational study in which 100 patients receiving Topiramate either monotherapy or an adjuvant drug along with conventional anti epileptic drugs, both were enrolled. The aim and procedure of the study were explained to the patients. Patients were asked questions related to the study, after explaining about the study in their own language. Only patients who were willing to participate and give informed consent were included. Written informed consent was obtained and patient's personal data like name, age, hospital number, educational status, occupation, mother tongue were noted. Also, symptoms, illness duration, past drug history and family history were also noted. Vital data and details of systemic examination were recorded. A note of the diagnosis and treatment prescribed was recorded in the proforma at each visit. Adverse drug reaction and clinical progress reported by the patient was also recorded in the proforma. Medication Adherence Questionnaire based on Liverpool Adverse Events Profile was used to record the adverse effects of topiramate. Mini Mental State Examination Tool was used to assess the cognitive function in patients. The following parameters were recorded.

- Gender

- Age

- Types of seizure disorders

- Dosage of Topiramate and Conventional antiepileptic drugs

- Adverse effects profile by Medication Adherence Questionnaire based on Liverpool Adverse Events Profile and Mini Mental State Examination tool.

\section{Statistical analysis}

The data were entered in Microsoft Excel Worksheet version 2007 and analyzed using GraphPad version 3.06, (GraphPad Software, USA 32 bit for Windows). The baseline data including demographic details, clinical history and details of the drug treatment were recorded in prevalidated case record form. Details of the adverse drug reactions recorded and analyzed.

\section{RESULTS}

For this study 100 patients receiving Topiramate as an adjuvant drug along with regular anti epileptic drugs were enrolled in the study for prescheduled three months.

Data of the patients were collected. Patients were followed up and adverse effects were noted. The results of the study revealed that out of 100 patients, 58 patients were males and 42 patients were females. In this study, there was a male preponderance as shown in Figure 1.

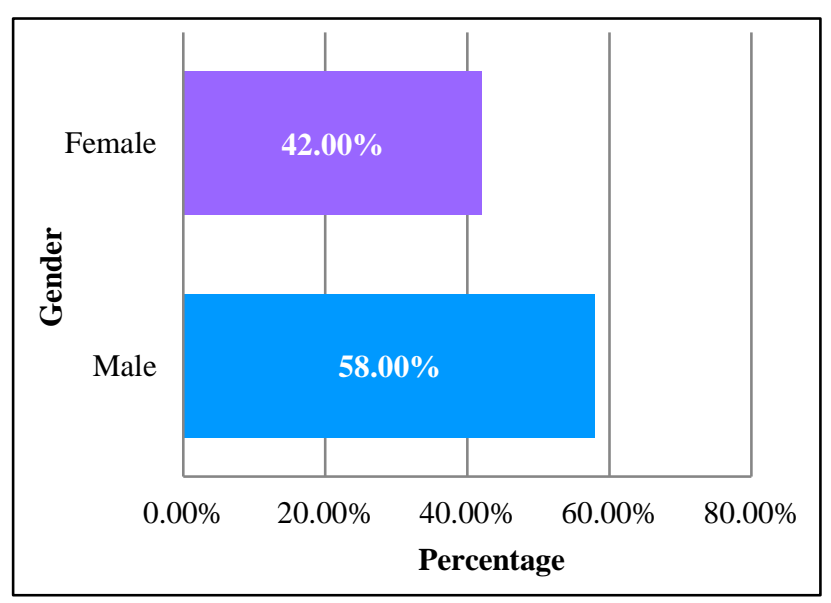

Figure 1: Details of gender distribution of patients.

Total $31 \%$ of the study population belongs to the age group of 31-40 years of age, 41-50 years of age was $27 \%, 20-30$ years of age was $23 \%$, and 51-60 years of age was $19 \%$ as shown in Figure 2.

Among 100 patients, patients with generalised tonic-clonic seizure, partial seizure, absence seizure and myoclonic 
seizure were $51 \%, 26 \%, 14 \%$ and $9 \%$ respectively as shown in Figure 3. In this study, topiramate $100 \mathrm{mg}$ was prescribed as an adjuvant along with regular anti epileptic drugs - phenytoin $100 \mathrm{mg}$, carbamazepine $200 \mathrm{mg}$ and phenobarbitone $60 \mathrm{mg}$. 57 patients were treated with topiramate and phenytoin, 28 patients with topiramate and carbamazepine and 15 patients with topiramate and sodium valproate as shown in Table 1.

Table 1: Drugs prescribed.

\begin{tabular}{|c|c|c|}
\hline $\begin{array}{l}\text { Name of drugs } \\
\text { used with } \\
\text { dose (mg) }\end{array}$ & $\begin{array}{l}\% \text { of } \\
\text { patients }\end{array}$ & Adverse effects \\
\hline \multirow{6}{*}{$\begin{array}{l}\text { Topiramate } 100 \\
+ \text { Phenytoin } \\
100\end{array}$} & \multirow{6}{*}{$57 \%$} & Paresthesia - $23 \%$ \\
\hline & & Cognitive impairment $-12 \%$ \\
\hline & & Sleepiness - 7\% \\
\hline & & Nausea- $7 \%$ \\
\hline & & Anorexia - 6\% \\
\hline & & Weight loss - $2 \%$ \\
\hline \multirow{6}{*}{$\begin{array}{l}\text { Carbamazepine } \\
200+ \\
\text { Topiramate } 100\end{array}$} & \multirow{6}{*}{$28 \%$} & Paresthesia - 5\% \\
\hline & & Cognitive impairment - 7\% \\
\hline & & Sleepiness - $6 \%$ \\
\hline & & Nausea- $5 \%$ \\
\hline & & Anorexia - 3\% \\
\hline & & Weight loss- $2 \%$ \\
\hline \multirow{4}{*}{$\begin{array}{l}\text { Sodium } \\
\text { valproate } 200 \\
+ \text { Topiramate } \\
100\end{array}$} & \multirow{4}{*}{$15 \%$} & Paresthesia $-3 \%$, \\
\hline & & Cognitive impairment $-5 \%$ \\
\hline & & Sleepiness - $6 \%$ \\
\hline & & Nausea - $1 \%$ \\
\hline
\end{tabular}

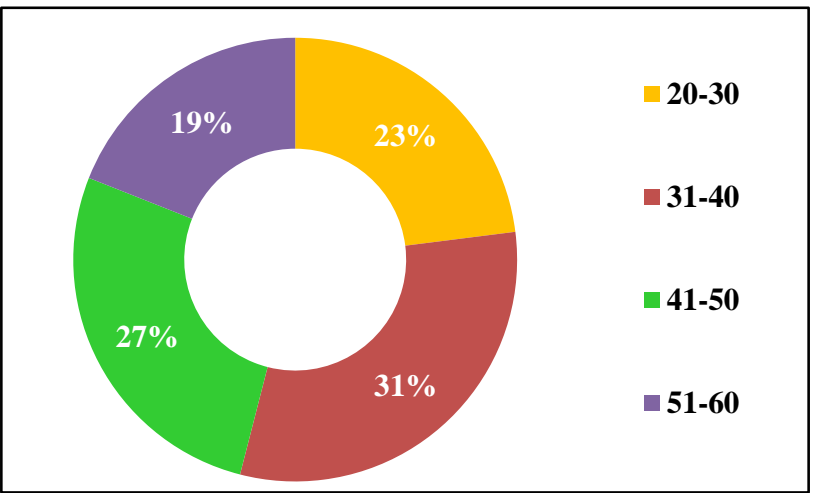

Figure 2: Age distribution of patients.

Among 57 patients taking topiramate and phenytoin, paresthesia was present in $23 \%$ of patients, $12 \%$ in cognitive impairment, $7 \%$ in sleepiness, $7 \%$ in nausea, $6 \%$ in anorexia and $2 \%$ in weight loss. Among 28 patients on topiramate and carbamazepine, $5 \%$ of patients developed paresthesia, $7 \%$ - cognitive impairment, $6 \%$ - sleepiness, $5 \%$ - nausea, $3 \%$ - anorexia and $2 \%$ - weight loss.

Among 15 patients taking topiramate and Sodium valproate, $3 \%$ of patients developed paresthesia, $5 \%$ - cognitive impairment, $6 \%$ - sleepiness and $1 \%$ - nausea as shown in Figure 4.

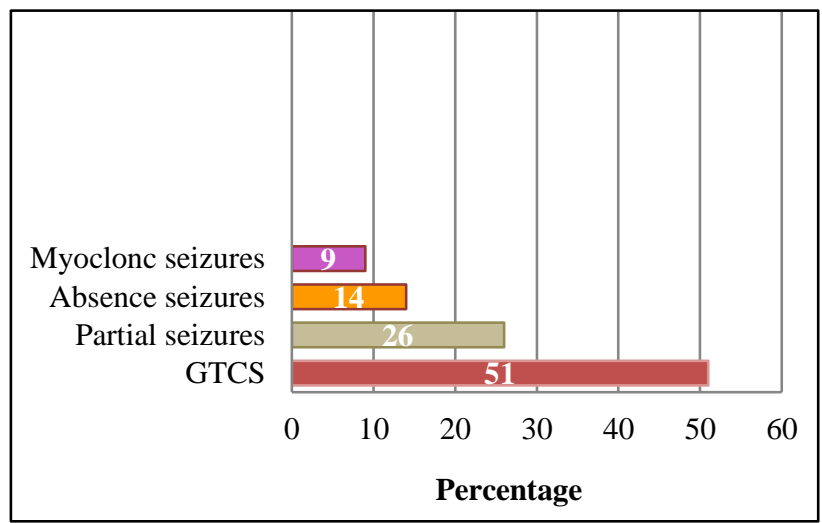

Figure 3: Details of disease distribution.

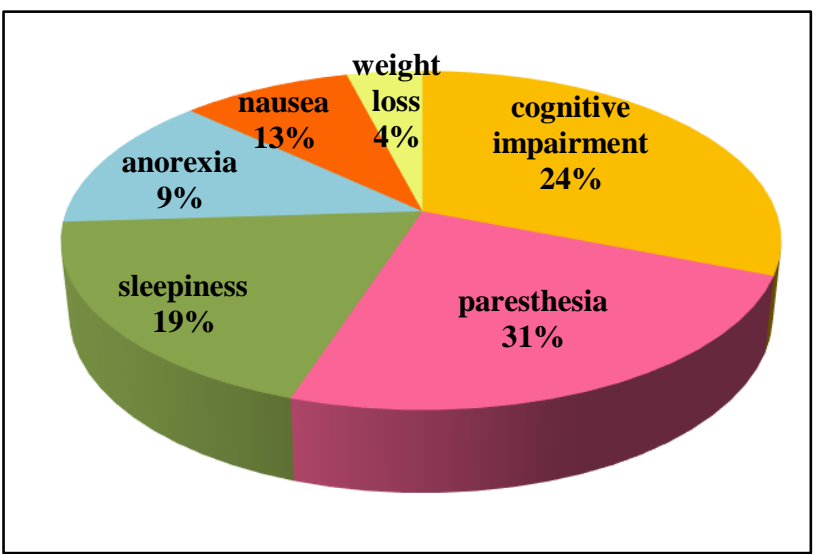

Figure 4: Details of adverse effects.

\section{DISCUSSION}

Topiramate is one of the more important of secondgeneration anti epileptic drugs. Optimal use of topiramate offers the possibility of better control for refractory patients, and often provides advantages in terms of ease of use and reduction of side effects. Topiramate was first tested in populations of patients with refractory partialonset seizures, as an adjunctive agent. The first trials in the United States enrolled adults taking one or two concomitant antiepilepsy drugs. Early results established excellent efficacy at all daily dosages of $200 \mathrm{mg}$ or more according to Faught et al, study. ${ }^{7}$

Clinical trials of topiramate as monotherapy demonstrated efficacy against partial and generalized tonic-clonic seizures. The drug is also approved for the Lennox-Gastaut syndrome, migraine headaches and may be effective in infantile spasms. Dosages typically range from 200 to 600 $\mathrm{mg}$ /day. Mostly the drug is prescribed at a low dose (50 $\mathrm{mg} / \mathrm{d}$ ) and is increased slowly to prevent adverse effects. Several studies have used topiramate in monotherapy with encouraging results. Although no idiosyncratic reactions have been noted, dose-related adverse effects occur most 
frequently in the first 4 weeks and include somnolence, fatigue, dizziness, cognitive slowing, paresthesias, nervousness, and confusion. Acute myopia and glaucoma may require prompt drug withdrawal. ${ }^{8}$ Topiramate may precipitate renal calculi (kidney stones), probably due to inhibition of carbonic anhydrase. ${ }^{9}$

According to Reife et al, study, topiramate does not produce life threatening adverse effects. ${ }^{10}$ According to Tatum et al, and Bootsma et al, studies, the most common reason for discontinuation is the occurrence of cognitive problems. ${ }^{11,12}$ Tolerability is improved by low initial doses with slow titration to the desired target dose in adults according to Biton et al, and Dodson et al, study. ${ }^{13,14}$ Reduction of the dosage of concomitant antiepileptic drugs is often effective in reducing central nervous system symptoms according to Naritoku et al, study. ${ }^{15}$

The adverse effects noted in the study group were paresthesia, cognitive impairment, sleepiness, weight loss, nausea and anorexia. Paresthesia (31\%) was the commonest adverse effect noted in this study followed by cognitive impairment (24\%), sleepiness (19\%), nausea $(13 \%)$, anorexia $(9 \%)$ and weight loss $(4 \%)$ as showed in Figure 4. Paresthesia could be occurred due to inhibition of carbonic anhydrase enzyme by topiramate. ${ }^{16}$ Previous studies showed that cognition impairment was the commonest problem encountered in patients with epilepsy taking topiramate. In this study we observed that paresthesia (31\%) was the commonest adverse effect followed by cognitive impairment $(24 \%)$.

\section{CONCLUSION}

In this observational study, we found that paresthesia was the commonly encountered adverse effect and it occurs due to inhibition of carbonic anhydrase enzyme by Topiramate followed by cognitive impairment and sleepiness. Topiramate is being widely used against most seizure types with additional indications for use in migraine headaches and shows a relatively favourable pharmacokinetic profile. It is appropriate for monotherapy as well as for adjuvant therapy in refractory patients with epilepsy. The major problem limiting its use is the frequent occurrence of cognitive adverse effects, especially expressive language dysfunction which are reversible upon discontinuation of the medication.

\section{ACKNOWLEDGEMENTS}

Authors would like to thank to the Department of Neurology for support. We thank the study participants and all the staff at the study centre, Govt. Stanley medical College, Chennai, Tamil Nadu, India.

Funding: No funding sources Conflict of interest: None declared

Ethical approval: The study was approved by the Institutional Ethics Committee

\section{REFERENCES}

1. Arroyo S, Dodson WE, Privitera MD (2005) Randomized dose controlled study of topiramate as first-line therapy in epilepsy. Acta Neurol Scand. 2005;112:214-22.

2. Sommer BR, Mitchell EL, Wroolie TE. Topiramate: effects on cognition in patients with epilepsy, migraine headache and obesity. Therapeutic advances in neurological disorders. 2013 Jul;6(4):211-27.

3. Lee S, Sziklas V, Andermann F, Farnham S, Risse G, Gustafson M, et al. The effects of adjunctive topiramate on cognitive function in patients with epilepsy. Epilepsia. 2003 Mar;44(3):339-47.

4. Thompson PJ, Baxendale SA, Duncan JS, Sander JW. Effects of topiramate on cognitive function. J Neurol Neurosurg Psychiatry. 2000 Nov 1;69(5):636-41.

5. Van Passel L, Arif H, Hirsch LJ. Topiramate for the treatment of epilepsy and other nervous system disorders. Expert Rev Neurotherapeut. 2006 Jan 1;6(1):19-31.

6. Jones MW. Topiramate-safety and tolerability. Canadian J Neurol Sci. 1998 Aug;25(S3):S13-5.

7. Faught E, Wilder BJ, Ramsay RE, Reife RA, Kramer LD, Pledger GW, et al. Topiramate placebo-controlled dose-ranging trial in refractory partial epilepsy using 200-, 400-, and 600-mg daily dosages. Neurol. 1996 Jun 1;46(6):1684-90.

8. Porter RJ, Rogawski MR. Antiseizure Drugs. In:Bertram G. Katzung's The Basic and Clinical Pharmacology. 14th ed. New Delhi, NY:Lange; 2018:427-428.

9. Misty D. Smith, Cameron S. Metcalf, and Karen S. Wilcox. Pharmacotherapy of the Epilepsies. In: Brunton LB, Randa Hilal-Dandan, C. Knollmann, eds. Goodman \& Gilman's The Pharmacological Basis of Therapeutics. 13th ed. New York, NY: McGraw-Hill; 2018:318-319.

10. Reife R, Pledger G, Wu SC. Topiramate as add-on therapy: pooled analysis of randomized controlled trials in adults. Epilepsia. $2000 \mathrm{Jan}$;41:66-71.

11. Tatum IV WO, French JA, Faught E, Morris III GL, Liporace J, Kanner A, et al. Postmarketing experience with topiramate and cognition. Epilepsia. 2001 Sep;42(9):1134-40.

12. Bootsma HP, Coolen F, Aldenkamp AP, Arends JB, Diepman L, Hulsman JA, et al. Topiramate in clinical practice: long-term experience in patients with refractory epilepsy referred to a tertiary epilepsy center. Epilepsy Behavior. 2004 Jun 1;5(3):380-7.

13. Biton V, Edwards KR, Montouris GD, Sackellares JC, Harden CL, Kamin M, Topiramate TPS-TR Study Group. Topiramate titration and tolerability. Ann Pharmacotherapy. 2001 Feb;35(2):173-9.

14. Dodson WE, Kamin M, Kraut L, Olson WH, Wu SC. Topiramate titration to response: analysis of individualized therapy study (TRAITS). Ann Pharmacoth. 2003 May;37(5):615-20.

15. Naritoku DK, Hulihan JF, Schwarzman LK, Kamin M, Olson WH. Effect of cotherapy reduction on 
tolerability of epilepsy add-on therapy: a randomized controlled trial. Ann Pharmacoth. 2005 Mar;39(3):418-23.

16. Dodgson SJ, Shank RP, Maryanoff BE. Topiramate as an inhibitor of carbonic anhydrase isoenzymes. Epilepsia. 2000 Jan;41:35-9.
Cite this article as: Subahan SP, Kulandaiammal M, Arunan S. Adverse effects of topiramate in patients with epilepsy in a tertiary care hospital: observational study. Int J Basic Clin Pharmacol 2019;8:720-4. 